\title{
Amnesia/Review
}

\section{Retrieval failure versus memory loss in experimental amnesia: Definitions and processes}

\author{
Ralph R. Miller ${ }^{1,3}$ and Louis D. Matzel ${ }^{2}$ \\ ${ }^{1}$ Department of Psychology, SUNY-Binghamton, Binghamton, New York 13902-6000, USA; ${ }^{2}$ Department of Psychology, \\ Rutgers University, Piscataway, New Jersey 08854, USA
}

\begin{abstract}
For at least 40 years, there has been a recurring argument concerning the nature of experimental amnesia, with one side arguing that amnesic treatments interfere with the formation of enduring memories and the other side arguing that these treatments interfere with the expression of memories that were effectively encoded. The argument appears to stem from a combination of (1) unclear definitions and (2) real differences in the theoretical vantages that underlie the interpretation of relevant data. Here we speak to how the field might avoid arguments that are definitional in nature and how various hypotheses fare in light of published data. Existing but often overlooked data favor very rapid (milliseconds) synaptic consolidation, with experimental amnesia reflecting, at least in part, deficits in retrieval rather than in the initial storage of information.
\end{abstract}

As most commonly conceived, "memory consolidation" refers uniquely to the processes by which newly acquired information, which is initially represented in ongoing synaptic transmission, comes over time to be encoded in a format that was independent of ongoing activity (and thus sensory stimulation) (Müller and Pilzecker 1900; McGaugh 1966). Fundamental to consolidation theory as it was originally formulated is that there were dual representational systems, one dependent upon ongoing neural transmission and the other dependent on enduring (i.e., structural/molecular) changes in the nervous system (e.g., pathway synthesis, facilitation of transmitter release, potentiation of sensitivity to transmitter binding, enhancement of membrane excitability) (for a review, see Matzel et al. 1998). Presumably there was a sequential dependence of the latter process (consolidation) on the former process (see Hebb 1949). Today it is widely recognized that there are a number of different molecular-structural representations that may be formed during memory storage, and that these representations become stable (i.e., "encoded") at very different rates and are dependent on different neuroanatomical sites (see Gibbs and Ng 1977; McGaugh 2000). This conceptualization of the consolidation process is often referred to as "system consolidation," although it should be noted that these different structural-molecular representations need not be sequentially linked (see Tully et al. 1994). Much recent attention has been devoted to system consolidation, which is relatively slow and measured in hours, days, or even months (see Kim and Fanselow 1992), as opposed to the earlier but still not fully answered questions of initial consolidation, which is generally assumed to occur in seconds or minutes. Although careless use of language has resulted in some confusion between these two related but different types of consolidation, some researchers distinguish them by using the expression "synaptic consolidation" (or "short-term molecular consolidation") for initial consolidation, which they differentiate from system consolidation (Nadel and Moscovitch 1997; Nader et al. 2000b; Dudai 2004). The focus of the present review is on initial synaptic consolidation, with the qualifier "initial" because system consolidation is likely to also involve changes in synaptic efficacy (e.g., those which potentiate the sensitivity to transmitter binding) (Kauer et al. 1988; Isaac et al. 1995). Questions concerning synaptic consolidation rates are to-

\footnotetext{
${ }^{3}$ Corresponding author.
}

E-mail rmiller@binghamton.edu; fax (607) 777-4890.

Article is online at http://www.learnmem.org/cgi/doi/10.1101//m.241006. day often viewed as antiquated issues. However (and despite its implications for much contemporary research), the rate at which the earliest "enduring" representation is formed is still a question on which there is not full agreement.

Today, almost no one questions the principle of synaptic consolidation theory, at least as it is broadly conceptualized. But controversy arises when one asserts, as is commonly done, that synaptic consolidation is relatively slow (measured in 10s of seconds or minutes as opposed to seconds or fractions of a second) and that system consolidation is very slow (measured in days or even years) (see Rempel-Clower et al. 1996). The strongest evidence for long duration processes being necessary for initial consolidation of memories comes from studies of experimental amnesia (for a review, see McGaugh 2000). In these studies, at varying times following one-trial training (which allows a precise definition of the time of "acquisition," although massed trial training also allows for relatively precise temporal specification), a treatment is administered that presumably either disrupts the labile memory before the synaptic consolidation process is complete (e.g., electrical stimulation of the brain) or disrupts processes presumably necessary for the consolidation process (e.g., through the inhibition of protein synthesis), which then stay disrupted at least until the representation of the training event in the form of electrochemical transmission has damped out. Both sorts of intervention are observed to disrupt later target performance in inverse relationship to the delay of the intervention following training. That is, the shorter the delay between training and intervention, the greater the performance deficit (i.e., experimental amnesia), although there are some reports of multiple critical periods that do not always peak immediately after training (see Gibbs and $\mathrm{Ng}$ 1977). This frequently observed monotonic temporal gradient in which older memories are less readily perturbed is somewhat paradoxical because older memories are often harder to recall. Nevertheless, these gradients for experimental amnesia are at least superficially consistent with the consolidation theory view that extended periods of time are necessary to establish enduring memories.

\section{Basic phenomena}

Despite facile support for the more common conceptualizations of consolidation theory, there has been and continues to be controversy concerning whether the temporal gradients generated with amnestic agents really reflect different degrees of completed consolidation. These concerns are largely based on three types of 
observations: the lability of reactivated old memories, reminder effects, and residual memory effects.

The lability of a reactivated memory refers to the finding that profound amnesia can be induced long after original learning if the amnestic agent is administered soon after the presentation of a stimulus from the original training situation (i.e., at a time at which the established memory is presumed to be once again represented in a state based upon ongoing neural transmission). Importantly, the amnesia induced immediately following the reactivating stimulus is greater than any systemic amnesia induced by the amnestic agent without the reactivation treatment, which typically has little or no effect. Presumably, the stimulus "reactivates" the target memory into a state of active neural transmission (Misanin et al. 1968; Przybyslawski and Sara 1997; Nader et al. 2000a). The experimental amnesia induced following reactivation of an old, previously consolidated memory is retrograde in much the same fashion as is amnesia induced very soon following training (see Mactutus et al. 1982).

Reminder effects refer to the observation that, long after amnesia has been induced, presentation of a so-called reminder stimulus prior to testing can result in restoration of behavior indicative of the original learning (Lewis et al. 1968; Quartermain et al. 1972). Typically, the stimulus that serves as the most effective reminder stimulus is the reinforcer from initial training (see Miller and Springer 1972). However, there are clear instances of recovery from experimental amnesia being induced with the target conditioned stimulus (CS) serving as the reminder stimulus (see Gordon and Mowrer 1980). Reminder treatments also produce recovery from amnesia that had been induced by amnestic agents administered following reactivation of an old memory (see Eisenberg and Dudai 2004 as well as Duvarci and Nader 2004).

Under select conditions, amnestic treatments administered soon after training fail to produce the expected amnesia. Such resistance of newly acquired memories to amnesia is sometimes more illuminating than is the disruption of relatively new memories. It suggests that the process disrupted by the amnestic agent is not critical for memory, at least at the time that the agent was administered. Residual memory effects, which have been long neglected in the literature, refer to three related types of observations. The first is that, if testing occurs soon enough after administration of an amnestic agent, little or no amnesia is observed, whereas, with delayed testing, conventional amnesia is seen (see Geller and Jarvik 1969; Miller and Springer 1971). This finding is important when the amnestic agent is one that is known to disrupt all ongoing electrochemical transmission because it indicates that a structural/molecular representation of the training information was already formed in the interval between the receipt of the target information and administration of the amnestic agent. Strong bilateral electroconvulsive shock (ECS) is such an amnestic agent (Sudha et al. 2004). Such ECS initially drives all neural transmission to near maximal levels (producing a tonic behavioral state), thereby disrupting any information that would have been coded in differential neural transmission. (It is worth noting that exactly this technique [although referred to as "saturation"] has more recently been used to assess the role of long-term potentiation [LTP] in memory storage. This strategy is based on the assertion that ECS drives synaptic transmission to a sufficiently high level that LTP will be uniformly induced throughout the brain [Barnes et al. 1994].) This initial tetanus following ECS is followed seconds later first by a clonic state (behaviorally seen as convulsions) and soon after by a period of very low neural electrical activity as measured in EEG (behaviorally seen as a coma-like state). The use of ECS as an experimental procedure to assess the nature of memory has been criticized in recent years for being systemic rather than anatomi- cally localized. Surely, knowledge concerning the roles of specific anatomical sites is desirable, but in some respects there is a virtue in a treatment being systemic (as in the strategy adopted by Barnes et al. described above). Only systemic amnesic agents such as ECS, which immediately produces massive neural firing followed by profound electrical silence throughout the brain, can be viewed as pervasively disrupting ongoing neural transmission, thereby leaving only memories that were already stable, that is, presumably encoded in a structural-molecular format (Miller and Matzel 2000). Thus, even temporary memory following such an amnestic agent suggests that information from training was already initially consolidated at the time of ECS. In the case of Miller and Springer (1971), the interval from onset of the reinforcer (i.e., footshock) in their one-trial instrumental avoidance situation to onset of the ECS was $10 \mathrm{sec}$. Testing of their rats at 15 min, but not $30 \mathrm{~min}$, following ECS indicated retention of information from training. The behavior of control groups was consistent with the view that the behavior observed 15 min following ECS was associative as opposed to being a nonassociative effect of ECS. The observed behavior cannot be attributed to short-term (i.e., electrochemical transmission) memory that decays over time because ECS produces maximal neural firing that massively disrupts ongoing neural transmission. This makes it highly unlikely that short-term memory representations could account for behavior indicative of retention when ECS occurs between training and testing. Thus, despite the fact that this behavior waned over longer retention intervals, the original observation of behavior reflecting training suggests that structural/ molecular consolidation occurred in $<10$ sec.

The second residual memory effect is that under some circumstances, such as extensive pre-training exposure to the training context (i.e., familiarization), amnestic treatments that radically disrupt ongoing neural transmission fail to produce amnesia under conditions in which amnesia would otherwise be profound (e.g., when the test trial is delayed long after the amnestic treatment) (Lewis et al. 1969; Miller 1970). This indicates that a representation of training in a more enduring format than ongoing neural transmission had to have already been established by the time of amnestic treatment. Miller (1970) examined rats in a one-trial passive avoidance task in which rats received a footshock upon stepping down from a platform. With only 500 msec between onset of the footshock and onset of ECS, he found no amnesia relative to control subjects that did not receive ECS provided that there was pre-training exposure to the experimental apparatus (i.e., exploration of the platform and the floor below it). This indicates that some sort or degree of consolidation had to have been completed in $<500 \mathrm{msec}$, which is far less than the times ordinarily attributed to even synaptic consolidation (McGaugh 1966). Pre-training exposure to the apparatus surely allowed some learning concerning the context, but, importantly, the footshock unconditioned stimulus (US) was not presented until training. Hence, no consolidation of memories of the US could have occurred during the pre-training exposure to the context. Of course if system consolidation is considered, it surely involves more than the establishment of a representational format beyond that of ongoing neural transmission. As previously stated, there are several, perhaps numerous, different forms of structural-molecular representations, with these various representations being established at different times following initial training. But presumably an amnestic agent that disrupts and then stops all ongoing electrochemical transmission (e.g., ECS) should produce irreversible amnesia if it occurs prior to establishment of the earliest of these structural-molecular representations.

The third residual memory effect is that, even with a long interval prior to testing and little pre-training exposure to the

\section{Learning \& Memory}

www.learnmem.org 
apparatus, almost all rigorously tested examples of experimental amnesia find the amnesia to be incomplete regardless of whether it is produced by disrupters of ongoing neural transmission such as ECS or by agents that are purported to prevent the formation of structural-molecular representations of training such as protein synthesis inhibitors. That is, even with parameters selected to maximize amnesia, some components of the behavior indicative of the training experience are often preserved. This is interesting because it, like the other two residual memory effects, suggests that some sort of enduring representation of the training experience must have been established in the interval between the onset of training and the disruption/termination of ongoing transmission (i.e., in the case of ECS). This conclusion must be qualified for inhibitors of protein synthesis because, when they are administered systemically, they typically suppress production of new proteins by about only 80\%-90\% (Flood et al. 1973; Fulton et al. 2005). Hence, the residual memory observed long after training despite administration of an inhibitor soon after training could possibly reflect consequences of new protein synthesis. For this reason, residual memory following ECS provides a stronger argument because ECS disrupts neural transmission throughout the brain (and does so in a temporally concise manner). An additional interpretative problem for amnesia produced by administration of inhibitors of protein synthesis is that, in addition to inhibition, they have effects on a multitude of cellular processes, so much so that they typically kill some percentage of the effected neurons (Routtenberg and Rekart 2005; Rudy et al. 2006). There is a need to dissociate these different consequences of inhibitors of protein synthesis that induce experimental amnesia.

\section{Accounts of experimental amnesia}

There are several alternative accounts of the temporal gradients seen in experimental amnesia. Here we briefly summarize them and consider how each addresses the three phenomena described above (the lability of memory following reactivation, the reminder effect, and residual memory effects). The first and oldest account is traditional (synaptic) consolidation theory, which assumes the slow establishment of a stable structural-molecular representation of a learning event as a result of perseverating neural transmission (Müller and Pilzecker 1900; McGaugh 1966). In this framework, depending on the specific amnestic agent used, experimental amnesia represents either direct disruption of the ongoing neural transmission representation of the learning event prior to the establishment of the more enduring structuralmolecular representation (e.g., by ECS) or the prevention of the establishment of a more enduring representation (e.g., by inhibitors of protein synthesis) during the normal life span of ongoing electrochemical neural activity (i.e., the representation of the sensory event). All three of the phenomena described above are problematic for traditional consolidation theory. Reactivation effects are incompatible because memories, once consolidated into a stable structural-molecular format, should not again become vulnerable to amnestic agents. Residual memory following administration of an amnestic agent that disrupts ongoing neural transmission is not itself incompatible with traditional consolidation theory because some consolidation might have already occurred prior to administration of the amnestic agent. However, it is unclear why that which initially survives disruption of electrochemical transmission then decays (i.e., residual memory is often observed following the administration of ECS, but then decays as a function of the retention interval) (see Miller and Springer 1971). More problematic for consolidation theory is the finding that, with prior extensive exposure to the experimental context, no amnesia at all is observed despite in some instances allowing only $500 \mathrm{msec}$ for the consolidation process (Miller 1970). Despite consolidation rates presumably differing between specific tasks, if establishment of a stable structural-molecular representation of a training event is anywhere near as slow as is assumed by traditional consolidation theory, one would not expect any consolidation to have occurred in $<500 \mathrm{msec}$. As the fastest rate of protein turnover in the mammalian brain is $>5 \mathrm{~min}$ (Kovigin and Loria 2006), this suggests that initial synaptic consolidation is not dependent on the synthesis of new proteins. Reminder effects are also not anticipated by consolidation theory. If establishment of a stable structural-molecular representation is prevented prior to the natural or induced cessation of all active neural transmission representations, there should be no way to obtain behavior indicative of initial training short of additional training.

Some researchers (see Gold and King 1974), however, have argued that reminder effects are not inconsistent with traditional consolidation theory. They take the view that the previously described residual memories are reactivated by the reminder stimuli and new learning results from the conjoint activation of the reactivated (old/weak) memories and the neural representation of the reminder stimuli (which typically are selected to avoid any physical pairing of the two associates constituting the target memory). This account of reminder effects has been controversial in part because of its implied definition of learning. Some researchers define learning as the formation of any new neural representation regardless of whether it involves newly presented stimuli, whereas other researchers reserve the term for input and storage of new information from the external environment. This difference reduces to the question of whether learning can take place with no new input of (relevant) information. Reorganizing previously acquired information (i.e., thinking about previously acquired information) certainly establishes new memories, but is this learning? Presumably every retrieval operation has the potential to result in the formation of new memories, but whether in the absence of new input from the external world this is to be regarded as new learning is a matter of how one defines learning. Consequently, no amount of data will provide an answer here. Surely we form memories of at least some of our thoughts, including thoughts that are generated without external eliciting stimuli. Everyone would be comfortable saying, "Yesterday I thought of a new way to solve that problem." But only some of us would be comfortable saying, "I learned something new while thinking about that problem yesterday." Furthermore, it is worth noting that "memories" that arise as a result of introspective processing of previously acquired information are prone to error (i.e., contain factual inaccuracies), leading some to argue that such recollections should best be described as "false memories" (see Bernstein et al. 2004; Loftus 2005).

Definitions aside, no doubt information processing occurs when a reminder stimulus is presented to an amnestic subject, and the consequence of that information processing is sometimes stored as a new memory. But reorganization of previously encoded information that is reactivated by a reminder stimulus is possible only if there is previously encoded information. According to consolidation theory, an amnestic treatment very soon after one-trial CS-US training, in which both the CS and US are novel, should prevent not only consolidation of the CS-US association but also consolidation of all other possible new associations to the CS and the US as well as nonassociative representations of the CS and US themselves. Consequently, there should be no memories for a reminder stimulus to reactivate. For the view that reminder treatments produce new memories to be credible, one must assume that some stable encoding did take place at the time of training despite the administration of an amnestic agent very soon following training. However, this assumption is 
contrary to the basic principle of consolidation theory that initial consolidation takes many seconds if not minutes. This is not a novel assertion. In 1973, Miller and Springer argued that, if amnestic agents prevent the formation of enduring structuralmolecular representations of training, as is assumed by traditional consolidation theory, then memories based on this training should not be later available to benefit from later reminder treatments. Yet, reminder effects are clearly observed both when amnesia is induced very soon following training (i.e., potentially speaking to synaptic consolidation) (see Lewis et al. 1968; Quartermain et al. 1972; Gordon and Mowrer 1980) and with longer intervals between training and administration of the amnestic treatment (i.e., speaking to system consolidation) (see de Hoz et al. 2004).

One might defend the traditional consolidation position by arguing that using a reinforcer as a reminder stimulus allows new learning about the affective attributes of the reinforcer. Perhaps the association between the two paired stimuli was previously consolidated, but information about the affective value of the US was not consolidated. Then using the US (i.e., reinforcer) as a reminder stimulus could allow relevant new learning about the task that could enhance later performance. But it is hard indeed to see what new relevant learning could occur when the reminder stimulus is a presentation of the CS by itself (see Gordon and Mowrer 1980) or when the reminder stimulus is a stressor with physical characteristics highly dissimilar to the reinforcer in training (Springer and Miller 1972). Task-irrelevant stressors can under certain circumstances enhance existing memories (Shors 2004) as can a number of pharmacological agents, but there must be some memory in place to be enhanced. Thus, reminder effects suggest that amnestic agents do not interfere with consolidation of the central dyadic relationship between the CS and US. In defense of the consolidation view of experimental amnesia, Gold and King (1974) have argued that, although reminder treatments do not alter behavior in naive animals, they do enhance performance with weakly performing subjects (sometimes misidentified as weakly trained subjects). That is, they argue that reminder treatments seem to enhance performance even when there is no impairment. However, Miller (1982) has presented evidence that so-called acquisition curves are at least in part a reflection of improved retrieval rather than continued learning across successive training trials. Hence, facilitated retrieval could account for improved performance after reminder treatments in both animals given little training and amnesic animals. (Later we speak directly to retrieval models of amnesia.) In addition, the argument that critical new learning occurs on a reminder trial does not reconcile traditional (synaptic) consolidation theory with the existence of residual memories from initial training being observed despite very short times between training and administration of the amnestic agent.

As a variant on traditional consolidation theory and with an eye toward accounting for the malleability of reactivated memories within a consolidation framework, Nader et al. (2000a; for an updating of this view, see Alberini 2005) accepted traditional consolidation theory but added the supposition that reactivation of a memory makes the previously consolidated memory temporarily labile once again in the same manner it was at the time of acquisition, and that this labile state ends as a result of so-called reconsolidation, which, similar to consolidation, presumably can be prevented by timely administration of an inhibitor of protein synthesis. Exactly how (or even if) phenomena attributed to disrupted reconsolidation differ from phenomena attributed to disrupted initial consolidation is still unclear (see Sara 2000; Debiec et al. 2002). Superficially, these two types of amnesia appear qualitatively similar in terms of the shapes of their temporal gradients for disruption. But the underlying mechanisms may well be different as suggested by a double dissociation between the molecular cascades that underlie the two processes, where initial consolidation requires brain-derived neurotrophic factor (BDNF) but not the transcription factor Zif268, and reconsolidation requires Zif268 but not BDNF (Lee et al. 2004). Moreover, Power et al. (2006; also see Mactutus et al. 1982; Eisenberg and Dudai 2004; Lattal and Abel 2004) has asserted that subjects recover from amnesia produced by an amnestic agent administered immediately following reactivation, which they suggest is unlike amnesia induced immediately after initial acquisition. However, this assumption (which Power et al. did not test) is contradicted by the observation that reminder effects can sometimes be obtained when the amnesia has been produced immediately following initial training (see Quartermain et al. 1972). Complicating interpretation, these reminder effects, similar to so many other observations concerning experimental amnesia, are obviously parameter dependent (for a failure to obtain reminder effects following amnesia produced after a reactivation treatment, see Duvarci and Nader 2004). Importantly, reconsolidation theory, similar to traditional consolidation theory, has trouble accounting for reminder effects for the same reasons already stated for traditional consolidation theory.

Residual memory effects have not yet been fully investigated with respect to amnestic agents administered following a reactivating stimulus. An additional problem for reconsolidation theory is that if memories become labile and must be reconsolidated with each use, one would consistently expect increasing inaccuracy of memories with increasing (nonreinforced) usage because each use temporarily leaves the memory vulnerable to distortion. However, rehearsal is a time proven means of strengthening memories and reducing distortion. At this early state in our understanding of reconsolidation, we think that there are insufficient data to conclude that amnesia induced immediately after training is fundamentally different from that induced following reactivation. Parsimony favors a common account until we determine if the few reported dissociations between the two types of amnesia are quantitative (i.e., merely parameter dependent) or qualitative.

Nadel and Moscovitch (1997) have proposed a multiple trace theory as an alternative to traditional consolidation theory. In their model, short-term consolidation occurs as in the traditional consolidation model, but, following that, each reactivation of a memory results in the formation of new copies of the original memory. The new copies can differ from prior copies in both content and neuroanatomical loci because somewhat different aspects of the overall representation of learning are activated on each reactivation trial. For Nadel and Moscovitch (1997), there is no time-dependent long-term consolidation. Rather, the greater stability often attributed to long-term consolidation merely reflects the increasing number of similar representations of the same training event. (These multiple traces are assumed to be distributed in the hippocampal complex and neocortex, but anatomical specificity is not germane to the present discussion, which focuses on synaptic consolidation.) The multiple trace model is appealing because it readily accounts for the great variety in slopes seen in different retrograde gradients. In addition, the theory is consistent with the reconstructive nature of memory that has been well documented by cognitive psychologists (Bartlett 1932). However, the multiple trace model does not appreciably differ from traditional consolidation theory with respect to synaptic (i.e., short-term) consolidation. Hence, it is not well equipped to account for experimental amnesia produced following reactivation or slowly waning residual memory effects. For example, if additional traces are formed with each reactivation, reactivation of a target memory should result in ever increasing stability of that memory, not temporarily in-

\section{Learning \& Memory}

www.learnmem.org 
creased lability (see Nadel and Land 2000). Any treatment that soon follows reactivation of an old memory might interfere with the formation of new memories based upon this reactivation but should not disrupt the old memory. One type of residual memory effect that multiple trace theory does begin to address is the enduring resistance to experimental amnesia for training events that occur in a highly familiarized context. Presumably, pre-training familiarization with the context creates many similar representations of the context, all of which can enter into association with the contingent stimuli that are introduced on the target training trial. This should encourage parallel processing (i.e., parallel consolidation) of information concerning the contingent stimuli, which should be faster than learning about the contingent stimuli in the absence of multiple previously acquired representations of the context. Moreover, the multiple trace theory provides an account of reminder effects by assuming that a reminder stimulus reactivates the target memory, which then results in additional copies of that memory or similar memories being laid down. However, the model provides no account of how the target memory survives amnestic agents administered immediately following training.

As a distinctly different alternative to consolidation theory accounts of experimental amnesia phenomena, Lewis et al. (1968) proposed that all amnestic agents examined to date act on operations necessary for later retrieval processes rather than on storage (i.e., consolidation) processes per se. They assumed that initial (i.e., synaptic) consolidation occurs in fractions of a second (see Miller 1970), and they accounted for the retrograde amnesia gradients by assuming that a period of time following learning (one that is far longer than is necessary for initial consolidation) is required for completion of processes that determine the efficacy with which the memory can be retrieved. While these processes that are necessary for later retrieval are occurring, they are vulnerable to disruption. Importantly, this view assumes a definition of consolidation that encompasses initial storage of information in a structural-molecular format (analogous to placing a book on the shelf of a library), but not the neural processing that presumably is necessary at the time of training in order to enable later retrieval (analogous to cataloging the book so it can be easily located in the future). This preparation for later retrieval, which occurs following synaptic consolidation, may be part or even all of what is often called system consolidation. Moreover, because amnesia produced in conjunction with both initial learning and reactivation treatment is subject to recovery through reminder treatments, Lewis et al. (1968) viewed experimental amnesia following reactivation as arising from activation of a retrieval pathway for a specific memory resulting in that pathway becoming temporarily labile following reactivation until the pathway restabilized. Duvarci and Nader (2004) argued against such a view on the grounds that they failed to observe either spontaneous recovery or reminder-induced recovery from amnesia induced after administration of a reactivating stimulus. However, these are null results and did not reflect parametric efforts to obtain sensitive parameters to obtain such effects, which are anticipated by the retrieval-failure account of experimental amnesia as proposed by Lewis et al. Moreover, other researchers have obtained reminder-induced recovery from amnesia induced after administration of a reactivating stimulus (see Land et al. 2000). The basis for these discrepancies is not yet clear, but may be attributable simply to differences in procedure (e.g., differences in amnestic treatments).

Lewis et al.'s (1968) retrieval theory views reminder stimuli as highly salient (i.e., effective) retrieval cues that overcome impaired retrieval and consequently allow reestablishment of the previously impaired retrieval pathway and/or the development of new retrieval pathways as suggested by multiple trace theory.
Moreover, in this retrieval-failure framework, the short-term residual memories, evident when testing occurs soon after a systemic amnestic treatment that momentarily terminates all ongoing electrochemical transmission (e.g., ECS), reflect the decay of training-specific "retrieval" pathways that did not stabilize prior to administration of the amnestic agent. Thus, retrieval theory is perhaps the only contemporary account that is able to explain all three of the basic phenomena described above. However, a weakness of this position is that it is not highly specific concerning the nature of these hypothesized retrieval pathways. In this regard, many neurobiological accounts of memory storage treat the retrieval process as a byproduct of the storage process; that is, sensory stimulation of the "storage pathways" elicits the behavior indicative of memory (for review, see Matzel et al. 1998). This view of memory expression is problematic within the framework of contemporary learning theory and is incompatible with much behavioral data (for reviews and discussion, see ; Rescorla 1988; Matzel and Shors 2001). It is similarly clear that these neurobiological descriptions of memory do not suffice to account for retrieval theory as it is proposed here, as they treat storage and retrieval as being subserved by a singular mechanism.

A variant of the above retrieval failure view of retrograde amnesia has long been advocated by Riccio and his colleagues (for summaries, see Millin et al. 2001; Riccio et al. 2003). They regard the internal physiological state of the subject that prevails immediately before, during, and after training as being an important retrieval cue at the time of testing. The amnestic agent presumably creates an internal context that is not ordinarily present at the time of testing. This position readily accounts for the retrograde gradient of experimental amnesia and receives strong support from studies that demonstrate recovery when the subject is re-exposed to the amnestic agent just prior to testing (see Hinderliter et al. 1975). Amnesia induced by an amnestic agent soon after reactivation of an old memory is viewed as the result of the old memory now being associated with the internal context created by the amnestic agent and that association interfering with the earlier acquired association between the internal training context and the target memory. In the view of Riccio, the effectiveness of reminder treatments is a consequence of the reminder stimulus and the internal state produced by the amnestic treatment having similar stimulus properties. This seems plausible when the reminder stimulus is stressful, but is harder to apply to situations in which the reminder stimulus is an innocuous cue from the original training situation (see Gordon and Mowrer 1980).

Some of the discrepancies in the literature could be resolved through a sharper distinction between initial (i.e., synaptic) consolidation and subsequent system consolidation, which is sometimes (arguably) thought to involve relocation of stored information to different anatomical sites in the brain (often from hippocampus to neocortext) (see Dudai 2004) over long, perhaps very long (e.g., days) periods of time (Kim and Fanselow 1992; Milekic and Alberini 2002). Protein synthesis inhibitors given following training are necessarily administered at least seconds if not minutes following training (and then take even longer to permeate the cell membrane and cytosol), which is more than enough time for synaptic consolidation to have occurred. Hence, protein inhibitors, if acting on consolidation at all, are likely to be acting exclusively on system consolidation rather than synaptic consolidation. ECS is unique in being deliverable in fractions of a second following the onset of reinforcement in one-trial training. Hence, it may be the only amnestic agent used to date that acts on synaptic consolidation. ECS also has the benefit of acting on the entire brain rather than only specific anatomical sites (of course there are distinct alternative advantages of using the localized amnestic agents that are commonplace today). Owing to 
both its rapidity of administration and its reach to the entire brain, ECS is a unique probe that might be worth returning to for answering certain questions today.

It is interesting to note that neuroscience's emphasis on consolidation (a storage processes), to the exclusion of other processes that are likely necessary for the expression of acquired behavior, is also often seen in studies of associative processes in animals outside the domain of neuroscience. Although $35 \mathrm{yr}$ old, the most widely cited associative model of learning is still that of Rescorla and Wagner (1972; for a review, see Miller et al. 1995), which focuses on acquisition uniquely and assumes that behavior is a perfect reflection of information that has been stored. This emphasis on processing at acquisition over processing at test is also seen in newer associative models of learning (see Van Hamme and Wasserman 1994). In the framework of these models, deficits in performance seen in situations in which acquired behavior might be expected are all attributed to a failure to encode information. For instance, the behavioral deficits collectively referred to as cue competition (e.g., overshadowing and blocking) are assumed to arise from the better predictor of the reinforcer preventing encoding (i.e., consolidation) of the contingent relationship between the lesser predictor and the reinforcer; little information processing of consequence is assumed to occur at the time of testing. Thus, we see that across disciplines researchers interested in storage processes tend to interpret deficits in behaviors indicative of learning largely in terms of storage failures. In contrast, there are a few recent nonbiological models of basic learning processes that do emphasize the roles of information retrieval and response generation processes (see Miller and Matzel 1988; Gallistel and Gibbon 2000). Notably, over the past $35 \mathrm{yr}$, cognitive psychologists working with human subjects, but largely in a nonbiological framework, have recognized the importance of retrieval (see Capaldi and Neath 1995) and decision processes (e.g., signal detection theory).

\section{Conclusions}

Acquired behavior, based on temporally distant prior experience, surely involves both long-term storage of acquired information in a structural/molecular format(s) and the later retrieval of that information into some sort electrochemical neural format dependent on synaptic transmission. The transmission format presumably is then subjected to a decision process to determine responding. If we ignore any of these stages of information processing, we cannot fully understand the bases of acquired behavior. It is unfortunate (for purposes of our understanding) that these different processes are not easily differentiated in that, above and beyond the storage of newly acquired information, preparation for retrieval appears to also occur at the time of acquisition. If one includes preparations for future retrieval as part of one's definition of consolidation, then amnestic agents seemingly do impair consolidation. But if one defines consolidation as merely storing acquired information, then it appears doubtful that experimental amnesia reflects interference with initial (i.e., synaptic) consolidation. Rather, experimental amnesia seems to arise from disruption of preparation for later retrieval and/or system consolidation. Moreover, existing data indicate that synaptic consolidation sometimes occurs in $<500 \mathrm{msec}$, which seems to preclude a role for protein synthesis. Finally, to move the field forward, it is important that we not confuse conceptual differences concerning neurophysiologic processes with definitional differences that merely reflect disagreement in how we use terms such as learning, synaptic consolidation, and system consolidation.

\section{Acknowledgments}

We thank Jeffrey C. Amundson, David Guez, Gonzalo P. Urcelay, Daniel S. Wheeler, and James E. Witnauer for their comments on an earlier version of the manuscript. Support for the preparation of this manuscript was provided by National Institute of Mental Health Grant 33881.

\section{References}

Alberini, C.M. 2005. Mechanisms of memory stabilization: Are consolidation and reconsolidation similar or distinct processes? Trends Neurosci. 28: 51-56.

Barnes, C.A., Jung, M.W., McNaughton, B.L., Korol, D.L., Andreasson, K., and Worley, P.F. 1994. LTP saturation and spatial learning disruption: Effects of task variables and saturation levels. J. Neurosci. 14: $5793-5806$.

Bartlett, F.C. 1932. Remembering: A study in experimental and social psychology. Cambridge University Press, Cambridge, UK.

Bernstein, D.M., Godfrey, R.D., Davison, A., and Loftus, E.F. 2004 Conditions effecting the revelation effect for autobiographical memory. Mem. Cognit. 32: 455-462.

Capaldi, E.J. and Neath, I. 1995. Remembering and forgetting as context discrimination. Learn. Mem. 2: 107-132.

Debiec, J., LeDoux, J.E., and Nader, K. 2002. Cellular and systems reconsolidation in the hippocampus. Neuron 36: 527-538.

de Hoz, L., Martin, S.J., and Morris, R.G.M. 2004. Forgetting, reminding, and remembering: The retrieval of lost spatial memory. PLoS Biol. 2: $1-22$.

Dudai, Y. 2004. The neurobiology of consolidations, or how stable is the engram? Annu. Rev. Psychol. 55: 51-86.

Duvarci, S. and Nader, K. 2004. Characterization of fear memory reconsolidation. J. Neurosci. 24: 9269-9275.

Eisenberg, M. and Dudai, Y. 2004. Reconsolidation of fresh, remote, and extinguished fear memory in medaka: Old fears don't die. Eur. J. Neurosci. 20: 3397-3403.

Flood, J.F., Rosenzweig, M.R., Bennet, E.L., and Orme, A.E. 1973. The influence of protein synthesis inhibition on memory. Physiol. Behav. 10: $555-562$.

Fulton, D.F., Kemenes, I., Andrew, R.J., and Benjamin, P.R. 2005. A single time-window for protein synthesis-dependent long-term memory after one-trial appetitive conditioning. Eur. J. Neurosci. 21: $1347-1358$.

Gallistel, R. and Gibbon, J. 2000. Time, rate and conditioning. Psychol. Rev. 107: 289-344.

Geller, A. and Jarvik, M.E. 1969. The time relations of ECS induce amnesia. Psychon. Sci. 12: 169-170.

Gibbs, M.E. and Ng, K.T. 1977. Psychobiology of memory: Towards a model of memory formation. Biobehav. Rev. 1: 113-136.

Gold, P.E. and King, R.A. 1974. Retrograde amnesia: Storage failure vs. retrieval failure. Psychol. Rev. 81: 465-469.

Gordon, W.C. and Mowrer, R.R. 1980. The use of an extinction trial as a reminder treatment following ECS. Anim. Learn. Behav. 8: 363-367.

Hebb, D.O. 1949. The organization of behavior. Wiley, New York.

Hinderliter, C.F., Webster, T., and Riccio, D.C. 1975. Amnesia produced by hypothermia as a function of treatment-test interval and recooling in rats. Anim. Learn. Behav. 3: 257-263.

Isaac, J.T., Nicoll, R.A., and Malenka, R.C. 1995. Evidence for silent synapses: Implications for the expression of LTP. Neuron 15: $427-434$.

Kauer, J.A., Malenka, R.C., and Nicoll, R.A. 1988. A persistent postsynaptic modification mediates long-term potentiation in the hippocampus. Neuron 1: 1183-1194.

Kim, J.J. and Fanselow, M.J. 1992. Modality-specific retrograde amnesia of fear. Science 256: 675-677.

Kovrigin, E.L. and Loria, J.P. 2006. Characterization of the transition state of functional enzyme dynamic. J. Am. Chem. Soc. 128: 7724-7725.

Land, C., Bunsey, M., and Riccio, D.C. 2000. Anomalous properties of hippocampal lesion-induced retrograde amnesia. Psychobiology 28: $476-485$.

Lattal, K.M. and Abel, T. 2004. Behavioral impairments caused by injections of the protein inhibitor anisomycin after contextual retrieval reverse with time. Proc. Natl. Acad. Sci. 101: 4667-4672.

Lee, J.L.C., Everitt, B.J., and Thomas, K.L. 2004. Independent cellular processes for hippocampal memory consolidation and reconsolidation. Science 304: 839-843.

Lewis, D.J., Misanin, J.R., and Miller, R.R. 1968. The recovery of memory following amnestic treatment. Nature 220: 704-705.

Lewis, D.J., Miller, R.R., and Misanin, J.R. 1969. Selective amnesia in rats produced by ECS. J. Comp. Physiol. Psychol. 69: 136-140.

Loftus, E.F. 2005. Planting misinformation in the human mind: A 30-year investigation of the malleability of memory. Learn. Mem. 4: 361-366.

Mactutus, C.F., Ferek, J.M., George, C.A., and Riccio, D.C. 1982. Hypothermia-induced amnesia for newly acquired and old reactivate 
memories: Commonalities and distinctions. Physiol. Psychol. 10: 79-95.

Matzel, L.D. and Shors, T.J. 2001. Long-term potentiation and associative learning: Can the mechanism subserve the process? In Neuronal mechanisms of memory formation: Long-term potentiation and beyond (ed. C. Holcher), pp. 148-195. Cambridge University Press, Cambridge, UK.

Matzel, L.D., Talk, A.C., Muzzio, I.A., and Rogers, R.F. 1998. Ubiquitous molecular substrates for associative learning and activity-dependent neuronal facilitation. Rev. Neurosci. 9: 129-167.

McGaugh, J.L. 1966. Time-dependent processes in memory storage. Science 153: 1351-1358.

. 2000. Memory: A century of consolidation. Science 287: 248-251.

Milekic, M.H. and Alberini, C.M. 2002. Temporally graded requirement for protein synthesis following memory reactivation. Neuron 36: $521-525$.

Miller, R.R. 1970. Effects of environmental complexity on amnesia induced by electroconvulsive shock in the rat. J. Comp. Physiol. Psychol. 71: 267-275.

1982. Effects of intertrial reinstatement of training stimuli on complex maze learning in rats: Evidence that "acquisition" curves reflect more than acquisition. J. Exp. Psychol. Anim. Behav. Process. 8: $86-109$.

Miller, R.R. and Matzel, L.D. 1988. The comparator hypothesis: A response rule for the expression of associations. In The psychology of learning and motivation (ed. G.H. Bower), pp. 51-92. Academic Press San Diego, CA.

. 2000. Memory involves far more than "consolidation." Nat. Rev. Neurosci. 3: 214-216.

Miller, R.R. and Springer, A.D. 1971. Temporal course of amnesia in rats after electroconvulsive shock. Physiol. Behav. 6: 229-233. . 1972. Induced recovery of memory in rats following ECS. Physiol. Behav. 8: 645-651.

. 1973. Amnesia, consolidation, and retrieval. Psychol. Rev. 80: $69-79$.

Miller, R.R., Barnet, R.C., and Grahame, N.J. 1995. Assessment of the Rescorla-Wagner model. Psychol. Bull. 117: 363-386.

Millin, P.M., Moody, E.W., and Riccio, D.C. 2001. Interpretations of retrograde amnesia: Old problems redux. Nat. Rev. Neurosci. 2: 68-70.

Misanin, J.R., Miller, R.R., and Lewis, D.J. 1968. Retrograde amnesia produced by electroconvulsive shock after reactivation of a consolidation memory trace. Science 160: 554-555.

Müller, G.E. and Pilzecker, A. 1900. Experimentelle beitrage zur lehre vom gedachtnis. Z. Psychol. SI: $1-300$.

Nadel, L. and Land, C. 2000. Memory traces revisited. Nat. Rev. Neurosci. 1: 209-212.

Nadel, L. and Moscovitch, M. 1997. Memory consolidation, retrograde amnesia and the hippocampal complex. Curr. Opin. Neurobiol.
7: 217-227.

Nader, K., Schafe, G.E., and LeDoux, J.E. 2000a. Fear memories require protein synthesis in the amygdala for reconsolidation after retrieval. Nature 406: 722-726.

. 2000b. The labile nature of consolidation theory. Na. Rev. Neurosci. 1: 216-219.

Power, A.E., Berlau, D.J., McGaugh, J.L., and Steward, O. 2006. Anisomycin infused into the hippocampus fails to block "reconsolidation" but impairs extinction: The role of re-exposure duration. Learn. Mem. 13: 27-34.

Przybyslawski, J. and Sara, S.J. 1997. Reconsolidation of memory after its consolidation. Behav. Brain Res. 84: 24-26.

Quartermain, D., McEwen, B.S., and Azmetia Jr., E.C. 1972. Recovery of memory following amnesia in the rat and mouse. J. Comp. Physiol. Psychol. 79: 360-370.

Rempel-Clower, N.L., Zola, S.M., Squire, L.R., and Amaral, D.J. 1996. Three cases of enduring memory impairment after bilateral damage limited to the hippocampal formation. J. Neurosci. 16: 5233-5255.

Rescorla, R.A. 1988. Behavioral studies of Pavlovian conditioning. Annu. Rev. Neurosci. 11: 329-352.

Rescorla, R.A. and Wagner, A.R. 1972. A theory of Pavlovian conditioning: Variations in the effectiveness of reinforcement and nonreinforcement. In Classical conditioning II: Current research and theory (eds. A.H. Black and W.F. Prokasy), pp. 64-99. Appleton-Century-Crofts, New York.

Riccio, D.C., Millin, P.M., and Gisquet-Verrier, P. 2003. Retrograde amnesia: Forgetting back. Curr. Dir. Psychol. Sci. 12: 41-44.

Routtenberg, A. and Rekart, J. 2005. Post-translational protein modifications as the substrate for long-term memory. Trends Neurosci. 28: 12-19.

Rudy, J.W., Biedenkapp, J.C., Moineau, J., and Bolding, K. 2006. Anisomycin and the reconsolidation hypothesis. Learn. Mem. 13: $1-3$.

Sara, S.J. 2000. Retrieval and reconsolidation: Toward a neurobiology of remembering. Learn. Mem. 7: 73-84.

Shors, T.J. 2004. Learning during stressful times. Learn. Mem. 11: $137-144$.

Springer, A.D. and Miller, R.R. 1972. Retrieval failure induced by electroconvulsive shock: Reversal with dissimilar training and recovery agents. Science 177: 628-630.

Sudha, S., Andrade, C., Mukundan, C.R., and Chandra, J.S. 2004. Spectral EEG effects in electroconvulsive shock stimulus parameters: The development of a rationale for the optimization of the ECT stimulus. J. ECT 19: 197-210.

Tully, T., Preat, T., Boynton, C., and Del Vecchio, M. 1994. Genetic dissection of consolidated memory in Drosophila. Cell 79: 35-47.

Van Hamme, L.J. and Wasserman, E.A. 1994. Cue competition in causality judgments: The role of nonpresentation of compound stimulus elements. Learn. Motiv. 25: 127-151. 


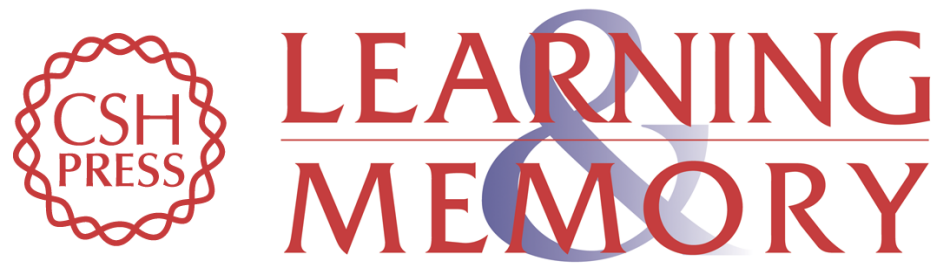

\title{
Retrieval failure versus memory loss in experimental amnesia: Definitions and processes
}

\author{
Ralph R. Miller and Louis D. Matzel
}

Learn. Mem. 2006, 13:

Access the most recent version at doi:10.1101/lm.241006

References This article cites 59 articles, 14 of which can be accessed free at: http://learnmem.cshlp.org/content/13/5/491.full.html\#ref-list-1

License
Email Alerting
Receive free email alerts when new articles cite this article - sign up in the box at the Service top right corner of the article or click here.

